\title{
GELENEKSEL BİR ÜRÜN OLARAK KASTAMONU PASTIRMASI
}

\author{
Kastamonu Pastrami as a Traditional Product
}

\author{
*Nuray TÜRKER \\ **B. Meltem TÜRKMEN \\ ***Esra CAYMAZ
}

\section{GAS}

Yayın Bilgileri

Kabul tarihi: 11.03.2019

Yayın tarihi: 28.03.2019

\section{Yazar Bilgileri}

*ORCID: 0000-0001-5701-5674

Email: nturker@karabuk.edu.tr

**ORCID :0000-0001-9953-1749

Email:mltmturkmen@gmail.com

***ORCID: 0000-0002-7569-7899

Email:esracaymaz33@gmail.com

\section{ÖZET}

Mutfak kültürü turizm çekicilikleri arasında önemli bir yer tutmaktadır. Günümüzde ulusal (Gaziantep, Antakya, Konya, İstanbul gibi) ve uluslararası (Örneğin, Toscana, şarap rotaları olarak Niagara, Stellensbosch, Napa Vadileri) pek çok destinasyon mutfak kültürleri ile ön plana çıkmaktadır. Bu bağlamda bu çalışmada Batı Karadeniz Bölümünde bulunan ve tarihi geçmişi yanı sıra lezzetli pastırması ile de dikkat çeken Kastamonu ilinde pastırma üretimi, pastırmanın tarihi, pastırma ile yapılan yemekler incelenmiştir. Çalışmada, nitel araştırma yöntemi kullanılarak Kastamonu'da pastırmacılık üretimini sürdüren dört işletmeci ile yapılan yüz yüze görüşmelerden elde edilen bulgular sunulmuştur. Sonuçlar, Kastamonu pastırmasının bilinen tarihinin 19. yüzyıl sonuna kadar dayandığını, pastırma üretiminin halen geleneksel yöntemler kullanılarak atölyelerde devam ettiğini, içeriğinde kullanılan malzemeler nedeniyle farklı bir aroma ve tada sahip olduğunu ve hediyelik eşya olarak ziyaretçiler tarafından önemli miktarda satın alındığını göstermektedir.

Anahtar Kelimeler: Kastamonu Pastırması, Mutfak Kültürü, Yöresel Ürün, Kastamonu.

\begin{abstract}
Culinary culture is a significant attraction for tourists. Today, national (such as Gaziantep, Antakya, Konya, Istanbul) and international (for example, Toscana, wine routes such as Niagara, Stellensbosch, Napa Valley) destinations having outstanding culinary culture attract a lot of tourists. In this context, in this study Kastamonu, which is located in the Western Black Sea Region and draw attention with its long history as well as delicious pastrami, pastrami production, history of pastrami, dishes made with pastrami were examined. In the study, using qualitative research method findings obtained from face-toface interviews with four producers in Kastamonu were presented. The results show that the known history of Kastamonu pastrami dates back to the end of the 19th century, that pastrami production still continues at workshops using traditional methods, that it has a different flavor and taste due to the ingredients used in its content, and that it is purchased in significant quantities as a souvenir.
\end{abstract}

Keywords: Kastamonu Pastrami, Culinary Culture, Local Food, Kastamonu. 


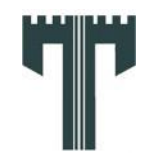

Gastroia: Journal of Gastronomy and Travel Research, Vol. 3, Issue 2, 2019

Geleneksel Bir Ürün Olarak Kastamonu Pastırması

Nuray TÜRKER, B. Meltem TÜRKMEN, Esra CAYMAZ

\section{GíRiş}

Türkiye'de her yörenin yemek kültürü ve beslenmesinde önemli yer tutan ve o yöreye özgü olan bazı geleneksel yiyecek ve içecekler bulunmaktadır (Gök, Sezgin ve Yıldırım, 2017: 62). Yörenin yemek kültürünü yansitan yiyecek ve içecekler, zaman zaman turistler için önemli çekim nedeni oluşturmakta ve destinasyonun çekiciliğini arttırmaktadır. Son yıllarda ortaya çıkan gastronomi turizmi köklü mutfak kültürüne, zengin, lezzetli ve özgün yemek çeşitliliğine sahip olan ülkelere ve bölgelere yönelik seyahatleri arttırmıştır. Yöresel ürünler gastronomi turistleri için önemli bir seyahat motivasyonu oluşturmaktadır. Araştırmalar (Kivela ve Crotts, 2005; Hashimoto ve Telfer, 2013, Dünya Turizm Örgütü, 2012), destinasyonun yemek kültürünün o yerin tercih edilmesinde önemli bir etken olduğunu ortaya koymaktadır. Dünya Turizm Örgütü Yiyecek Turizmi Küresel Raporu'na (2012) göre turistlerin \% 88,2'si destinasyon seçerken yemek konusuna dikkat etmektedirler. Türkiye'de Gaziantep, Antakya gibi şehirler lezzetli ve zengin yemek kültürleri nedeniyle önemli sayıda ziyaretçi almaktadır. Gaziantep gastronomi turizmi bakımından ülkemizin marka şehridir. Diğer yandan bir destinasyonu ziyaret eden turistler beslenmek için yiyecek-içecek tüketmek zorundadır. Araştırmalar (Sirše, 2014; Tefler ve Wall, 2000) turist harcamalarının üçte birinin yiyecek içecek harcamalarından oluştuğunu göstermektedir. Devlet İstatistik Enstitüsü'ne göre (2012), Türkiye'de turistik harcamaların $\% 25,7$ 'si yiyecek-içecek için yapılmaktadır.

Turistler seyahatleri sırasında genellikle yöreye özgü ürünleri tatma eğilimindedirler. Örneğin; Rizaoğlu, Ayazlar ve Gençer (2013) İngiltere'yi ziyaret eden turistlerin \% 72'sinin tatilleri süresince yöresel yemeklere ilgi duyduklarını belirtmektedir. Nitekim Aslan, Güneren ve Çoban (2014) Nevşehir'de yaptıkları araştırmada yöresel yemeklerin menüdeki diğer yemeklere göre daha çok tercih edildiğini saptamışlardır.

Bir yörenin kültürünü yansitan geleneksel ürünler yörenin bulunduğu coğrafi koşullar ve iklim şartlarına göre şekillenmekte ve yöreye özgü farklı yöntemler ile özgün bir şekilde üretilmektedir (Gök, Sezgin ve Yıldırım, 2017: 2). Pek çok yörede üretilen ve oldukça lezzetli bir ürün olan pastırma Türk mutfağında önemli bir yere sahiptir. Bu bağlamda bu çalışmada Kastamonu ilinin yöresel mutfak kültüründe önemli bir yer tutan Kastamonu pastırması, pastırmasının tarihsel önemi, pastırma yapımı için kullanılan et ve kalitesi, üretim süreci, pastırma ile yapılan yemekler incelenmiştir. Çalışmada, Kastamonu'da faaliyet gösteren dört pastırma üreticisi ile yapılan görüşmelerden elde edilen bulgular sunulmaktadır.

\section{PASTIRMA: TARIHİ VE ÜRETIMI}

Göçebe bir toplum olan eski Türklerde yiyecek olarak kullanılan en önemli besin maddesi hayvansal ürünlerdir. Pastırma, etin uzun süre dayanabilmesi amacıyla kullanılan bir saklama yöntemidir (Kızıldemir, Öztürk ve Sarışık, 2017). Türkçe bir isim olan Pastırma kelime anlamı itibariyle basmak anlamına gelen "bastırmak" fiilinden türemiştir (Gürbüz, 2004:6).

İlk kez Orta Asya Türkleri tarafından üretilen pastırma, göçebeliğin bir gereği olarak ortaya çıkmıştır. Pastırmanın, Orta Çağda Avrupa'ya akın eden Orta Asya halkları Hun ve Oğuz Türkleri tarafından yiyecek maddesi olarak tüketildiği ve Selçuklular tarafından 


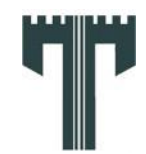

Gastroia: Journal of Gastronomy and Travel Research, Vol. 3, Issue 2, 2019

Geleneksel Bir Ürün Olarak Kastamonu Pastırması

Nuray TÜRKER, B. Meltem TÜRKMEN, Esra CAYMAZ

Anadolu'ya getirildiği bilinmektedir (Aksu ve Kaya, 2001:319; Memiş ve Ersoy, 2007:880). Türkler için önemli bir besin maddesi olan pastırma özellikle akınlara giden askerlerin, beslenme ihtiyaçlarını karşılamaktaydı. Atın eğeri altında saklanan et yol boyunca eğer ve diğer düzeneklerle sıkışmakta ve terleyen atın tuzu ile de birleşerek pastırma halini almaktadır (Kök, 2003:110; Kılıç ve Albayrak, 2012:710; Kızıldemir, Öztürk ve Sarışık, 2014:194).

Osmanlı İmparatorluğu kayıtlarında Pastırma adlı bir yiyeceğe 16. yüzyıl kaynaklarında rastlanmaktadır (And, 2011). Dönemin toplumsal hayatını anlatan Mevâidü'ün-Nefâis fî Kavâidi'l-Mecâlis'te içki meclisi hakkında bilgi verilirken meze olarak yenen pastırmadan bahsedilmektedir. Benzer biçimde, Topkapı Sarayı arşivinde bulunan ve 16. yüzyıla ait olduğu tahmin edilen bir belgede yer alan yemek listesinde pasdırma kış mevsiminde yenen yemekler arasında sayılmaktadır (Sarı 1982:250). Keza Padişah II. Ahmet'e (16911694) ait bir fermanda pastırma ile ilgili bazı hususlar sıralanmıştır (Kök, 2003:110). Pastırma hakkında en ayrıntılı bilgiye Evliya Çelebi Seyahatnamesi'nde rastlanmaktadır. Evliya Çelebi'nin Seyahatnamesine göre 17. yüzyılda pastırma, padişahtan cephedeki askere kadar herkesin tükettiği bir gıdadır. Üretimi ve pazarıyla büyük bir ekonomik değere sahiptir. Pastırmanın ticari üretimine 17. yüzyılda başlandığı bilinmektedir (Kök, 2003; Özkan, 2013:48).

"İstanbul önemli bir pastırma üretim merkezidir. Her yıl Kasım ayında yani pastırma zamanında Eflak ve Boğdan'dan Hıristiyan celepler pastırma yapımı için İstanbul'a yüz binlerce sığır getirir ve 40 gün boyunca Yedikule dışında kurulan pazarda bu hayvanları pazarlarlar. Kesilen hayvanların etleri çoğu Ermeni olan pastırmacılara, sucukçulara ve diğer kasaplara ve sakatatçılara satılır" (Özkan, 2013:48).

Evliya Çelebi seyahatnamesinde 17. yüzyıl Osmanlı mutfağında padişahlara hediye olarak götürülen bir Kayseri pastırmasından da bahsedilmektedir (Özkan, 2013:50). Bu durum Kayseri'nin çok eski zamanlardan bu yana önemli bir pastırma üretim merkezi olduğunu göstermektedir. Kök (2003), Anadolu'da pastırma üretiminin iklimin uygunluğu nedeniyle özellikle Kayseri'de geliştiğine dikkat çekmiştir.

Kayseri pastırması etin sığırdan alındığı bölüme göre; antrikot, kuşgömü, arkabaş, şekerpâre, tütünlük bacak, bohça, bohça eniği, but dilmesi, döş, eğrice, etek, kanlıbez, kapak, kavrama, kelle, kenar, kürek, kürek dilmesi, mehle, meme, omuz, ortabez, potuk, sırt gibi isimlerle anılır. Bunlar arasında en kaliteli olan pastırma kuşgömü ve sırt pastırmasıdır (Özkan, 2013:51). Kayseri pastırması sinirleri alınmış kaba etin ağaçtan oyulmuş teknelerde üzerine ağırlık konup "bastırılması" ile yapılır. Birkaç kez yapılan bu bastırma sonucunda etin suyu ve kanı akmış olur. Kan ve sudan arınmış olan et, çok sıcak olmayan günlerde iplere asılarak kurumaya bırakılır. Tavını aldıktan sonra da üzerine "çemen" sürülerek yenecek duruma getirilir (Gülensoy, 2011: 689).

17. yüzyıldan sonraki dönemlerde Anadolu'da pastırma yapımının geliştiği ve çeşitlendiği görülmektedir. 19. yüzyıla ait bir yemek kitabında Kayseri pastırması, Çemenli Kayseri pastırması, Rumeli pastırması, Tavuk pastırması ve Çerkez pastırması olmak üzere pastırmanın beş farklı çeşidinden bahsedilmektedir (Kut, 1985: 45:63-64). Kök (2003) on y1l öncesine kadar pastırma denince akla gelen ilk ilin Kayseri olduğunu belirtmektedir. 


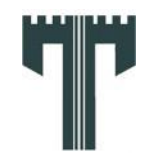

Gastroia: Journal of Gastronomy and Travel Research, Vol. 3, Issue 2, 2019

Geleneksel Bir Ürün Olarak Kastamonu Pastırması

Nuray TÜRKER, B. Meltem TÜRKMEN, Esra CAYMAZ

Ancak günümüzde Kastamonu, Kahramanmaraş, Erzurum, Ankara, Sivas, İstanbul, Adapazarı, Afyon ve Gaziantep, Kars yörelerinde de pastırma üretilmektedir.

Pastırma Anadolu'nun büyükbaş hayvancılık yapılan çeşitli yörelerinde üretilmektedir. Memiş ve Ersoy (2007), Yozgat yaylası, Sivas, Gemerek, Maraş, Çukurova, Erzurum ve Kars yaylasında yetiştirilmekte olan sığırların pastırma için elverişli olduğunu belirtmektedir.

Pastırma genellikle sığır ve manda etinden yapılır. Ancak günümüzde ticari olarak hindi etinden ve deneysel olarak da balık ve tavuk etinden pastırma üretilmektedir. Pastırma, hayvanların uygun bölgelerinden çıkartılan etin kurutulup çemenle kaplanması ile elde edilir. Pastırma üretimi, kullanılan karkasların büyüklüğüne göre yaklaşık 1 ay sürmektedir. Etin elde edildiği yere göre olgun bir sığır gövdesinden 26 farklı tür pastırma üretilebilmektedir. Kaliteli bir pastırma hayvanın fileto, gövde, bacak ve sırt kısımlarından elde edilir. Kesilen ve kas ve yağlarından ayrılan et 4-8 saat oda sıcaklığında dinlendirilir ve sonrasında pastırma yapmak için bölümlere ayrılır. Parçalara ayrılan et tuzlanarak 24 saat bekletilir. Tuzlama, gıda ürünlerinin muhafaza edilmesinde kullanılan en eski saklama yöntemlerinden biridir. Gıda maddesi içindeki bakteri, maya ve küflerin çoğalmalarını önler. 24 saat tuzda dinlenen etin tuzu yıkanır ve kurumaya bırakılır. Bu kurutma süresi 310 gün sürer. Kurutulan pastırmanın dış yüzeyi sarımsak, kırmızıbiber, çemen tozundan hazırlanan hamurla kaplanır ve 1-2 gün daha kurutulur (Kılıç, 2009: 584; Yıldırım vd., 2017: 153; Gürbüz, 2004: 6; Kök, 2003: 110). Çemen macunu, bir yandan yüzeydeki küf ve bakteri gibi bazı mikroorganizmaların üremesini engellerken, diğer yandan pastırmaya hoş bir lezzet ve aroma katar (Öztürk, 2015:76; Nizamlığlu ve diğerleri, 1998: 300).

Pastırma birinci, ikinci ve üçüncü sınıf olmak üzere üç kategoride değerlendirilir. Birinci sınıf pastırmalar hayvanın kuşgömü ve sırt kısmından elde edilen pastırmalardır. İkinci sınıf pastırmalar, bohça (eğrice), kenar, şekerpare, but dilmesi, mehle, omuz, kürek ve kapak kısmından elde edilir. Üçüncü sınıf pastırmalar ise etin bacak, döş, etek, kavram, bez, meme, kelle gibi bölümlerinden elde edilir (Özkan, 2013: 51; Milli Eğitim Bakanlığı, 2016:40).

2009 yılında yayınlanan Gıda Sanayi Envanteri'ne göre Türkiye'de 100 tane pastırma firması bulunmaktadır. Türkiye'de pastırma üretimi yılda 2500 ton olarak gerçekleşmektedir (Tosun ve Demirbaş, 2012: 96).

\section{KASTAMONU PASTIRMASI VE ÖZELLIKLERİ}

Son yıllarda giderek gelişen kültür turizmi destinasyonlardan biri olan Kastamonu zengin ve köklü bir yemek kültürüne sahiptir. Kastamonu'yu diğer destinasyonlardan ayıran en önemli özelliklerden biri de geleneksel yöntemlerle üretimi devam eden pastırma, kel simit, Kastamonu Helvası gibi yöresel lezzetleridir. Ünlü yemek araştırmacısı ve gurme Mehmet Yaşin'e göre Kastamonu, ülkemizin en önemli 10 gastronomi şehri arasında yer almaktadır. Yaşin, geleneksel yöntemlerle üretilen Kastamonu pastırmasının yükselen bir değer olduğuna dikkat çekmektedir (Hürriyet Gazetesi, 2016).

Kastamonu pastırması, küçük işletmelerde, ustaların bilgi birikimi ve becerisine dayalı olarak doğal koşullarda ve geleneksel yöntemlerle üretilmektedir (Aksu ve Kaya, 2001). Kastamonu pastırmasını, diğer pastırmalardan ayıran en temel özellik, üretimin endüstriyel 


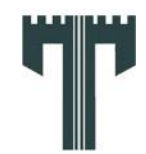

Gastroia: Journal of Gastronomy and Travel Research, Vol. 3, Issue 2, 2019

Geleneksel Bir Ürün Olarak Kastamonu Pastırması

Nuray TÜRKER, B. Meltem TÜRKMEN, Esra CAYMAZ

olmaması halen daha küçük üreticiler tarafindan geleneksel yöntemlerle üretilmesidir. Kastamonu pastırması doğal ortamda 30-45 gün askıda bırakılıp kurutularak elde edilir. Kastamonu pastırmasının rengi daha koyudur ve yumuşak dokuludur. Değişen beslenme alışkanlıkları nedeniyle önceleri üretimde siyah sığır ırkının yağlı etleri kullanılırken artık günümüzde yağsız etler kullanılmaktadır. Olgunlaştırma işlemi hala eski ve doğal yöntemlerle yapılan Kastamonu pastırması, ekim-kasım aylarına denk gelen pastırma yazı olarak bilinen dönemde kurutulmaktadır. Kastamonu pastırmasının en önemli özelliklerinden biri de çok ince kesilmesidir. Bu amaçla çok keskin bıçaklar kullanılır (Anadolu Lezzet Envanteri, 2016).

Tablo 1: Kastamonu Pastırmasının Özellikleri

Geleneksel yöntemlerle üretilir. Endüstriyel üretim yapılmaz.

Hayvanın 12 adet bölümünden elde edilen kaliteli etler kullanılır.

Çemen yapımında güçlü bir aromaya sahip olan Taşköprü sarımsağı kullanılır.

Çemen yapımında kimyasal maddeler, koruyucular kullanılmaz.

Kesimi elle keskin bıçaklar kullanılarak yapılır. Çok ince doğranır.

Diğer yörelerin pastırmalarına göre daha koyu renklidir ve daha yumuşaktır.

Kastamonu pastırmasının lezzet sırrı yörede yetişen hayvanların etinden ve çemeninde kullanılan Taşköprü sarımsağından kaynaklanmaktadır. Kastamonu pastırması çemenli veya çemensiz olarak üretilmekte, özellikle çemensiz pastırma Kastamonu mutfağının önemli lezzetlerinden birisi olan pastırmalı ekmek yapımında kullanılmaktadır. Ayrıca, pastırma ince dilimler halinde kesilerek genellikle kahvaltılarda da tüketilmektedir.

\section{YÖNTEM}

$\mathrm{Bu}$ araştırmanın amacı, Kastamonu pastırmasının üretim sürecini, üretimde kullanılan et çeşidini ve diğer malzemeleri (çemen gibi), pastırmanın ekonomik değerini, üretim miktarını ve pastırmadan yapılan yöresel yemekleri incelemektir. Bu amaçla çalışmada; makale, kitap, gazete yazıları gibi ikincil kaynaklar ile yüz yüze görüşme yöntemi ile elde edilen birincil verilerden yararlanılmıştır. Aralık 2017 itibariyle Kastamonu'da pastırma üretimi yapan 7 işletme bulunmaktadır. Nitel araştırma yöntemi kullanılan bu araştırmada Kastamonu'da pastırmacılık ile ünlenmiş ve aile mesleği olarak devam eden dört işletme ile Aralık 2017 döneminde yüz yüze görüşme gerçekleştirilmiştir. Görüşmede 15 sorudan oluşan yarı yapılandırılmış bir görüşme formu kullanılmış ve 15-20 dakika süren görüşmeler ses kayıt cihazı ile kaydedilmiştir. Alınan ses kayıtları betimsel olarak analiz edilmiştir.

Çalışmada işletmecilere işletmenin kuruluş yılı, işletmenin adı, görüşülen kişinin adı, işletmenin tarihi Kastamonu'da pastırmacılığın tarihi, pastırma üretim tekniği, yıllık üretim miktarı, pastırmanın maliyeti, fire miktarı, elde edilen kar, satış-pazarlama faaliyetleri konularında sorular yöneltilmiştir. Araştırmanın geçerlilik ve güvenilirliği için, işletmelerin iş yoğunluğu dikkate alınarak en uygun oldukları zaman seçilmiştir. Çalışmanın amacı görüşmeciye belirtildikten sonra görüşme soruları yöneltilmiştir. Kastamonu'da yedi pastırma işletmesi bulunmakla birlikte görüşme yapılan dört işletmeden elde edilen bilgiler tekrarlardan oluştuğu için görüşmeler sonlandırılmıştır. 


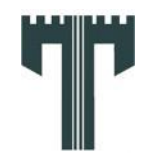

Gastroia: Journal of Gastronomy and Travel Research, Vol. 3, Issue 2, 2019

Geleneksel Bir Ürün Olarak Kastamonu Pastırması

Nuray TÜRKER, B. Meltem TÜRKMEN, Esra CAYMAZ

\section{BULGULAR}

Kastamonu'da pastırma üretimi yapan dört işletmeciyle yüz yüze görüşme yöntemiyle yapılan çalışmadan elde edilen bulgular aşağıda verilmektedir. Görüşme yapılanların bir tanesi kadın, üç tanesi ise erkektir. Yaş ortalamaları 45'tir. Ortalama 27 yıldır pastırma üretimi ile uğraşmaktadırlar.

\section{Kastamonu'da Pastırmacılığın Tarihi}

Kastamonu'da pastırmacılığın tarihi ile ilgili kesin bir bilgi olmamasına rağmen bölgede pastırmacılığın tarihinin 1800'lü yıllara kadar uzandığı tahmin edilmektedir. Görüşmelerden elde edilen bilgiler bölgede pastırmacılığın 150-200 yıldır yapıldığını göstermektedir.

K2: “...Pastırmacılık dede mesleği. İşletmemizin tarihi 1870 yılına kadar uzanıyor. Aile mesleği olan pastırmacılığa beş kuşaktır devam ediyoruz. ..........Kastamonu köklü bir tarihe sahiptir. İstila görmemiştir. Osmanlı döneminde İstanbul'un başkent olmadan önce buraya bağlı olduğu düşünülürse şehrin çok eski bir tarihi olduğu ortaya çıkmaktadır. Şehrin pastırma için uygun hava ve iklim şartlarına sahip olması pastırmacılığın gelişmesini sağlamıştır. Kastamonu'nun sahip olduğu karasal iklim pastırmacılıkta çok önemlidir. Çünkü pastırmacılık kuru iklime sahip yerlerde daha iyi sonuçlar verir, rutubetli hava pastırma için uygun değildir. Kastamonu'nun geniş yaylalara sahip olması hayvancılığ geliştirmiştir"

K4: “...Ben 13 yıldır pastırmacılık yapıyorum fakat aile işletmemiz yaklaşık 95 yıllık bir geçmişe sahip. Şuanda pastırmacılığı devam ettiren dördüncü kuşağım.”

\section{Pastırma Yapımında Kullanılan Et ve Hayvanın Bölümleri}

Geleneksel Kastamonu pastırmasında da Türkiye'de pastırma üretimi için kullanılan et bölümleri kullanılmaktadır.

K3: “...But, sırt, kuşgömü, antrikot, bonfile, but burnu, kuyruk sokumu, tembel, tarak melhesi (kaburganın olduğu bölge), kavram (karın altı), kol, kürek gibi hayvanın 12 bölgesinden pastırma üretiriz."

K4: “...Tarak melhesi, tıranç, kürek, nuar (dönerlik), rosto, kontro nuar, tembel (sırt ya da tütünlük, antrikot)), kontrofile, bonfile (kuşgömü) bölümlerini pastırma yapımı için kullanırız."

\section{Kastamonu Pastırması Üretim Süreci}

Kastamonu pastırmasının üretim süreci ile ilgili olarak yapılan görüşmelerden elde edilen bilgiler aşağıda verilmektedir:

Kastamonu'da pastırma mevsimi sonbahardır. Pastırma üretiminde Kastamonu ve civarında yetişen büyükbaş hayvanlar tercih edilir. Geçmişte düveden hazırlanan Kastamonu pastırması için günümüzde dana eti kullanılmaktadır. Dana etinin sırt, kuşgömü, but ve antrikot kısımları pastırma şekli verildikten sonra 3 gün kaya tuzunda bekletilir. Bu tuzlama alanlarına tuzlama yeri denir. Sonrasında su dolu bir kap içerisinde bastırılıp çıkartılarak yıkanan 'Kakaç' adı verilen bu et parçaları kınnaplara takılır ve sayvanlara asılarak güneşte kurutulur (Sayvanlar genellikle evlerin çatı kısmında bulunur ve bol güneş alır. İçerisinde etleri dizmeye yarayan kalaslar mevcuttur). Ilgaz dağlarından gelen ve pastırmanın kurumasını sağlayan kuru havanın Ankara yolu üzerinde bulunması 


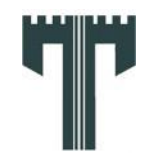

Gastroia: Journal of Gastronomy and Travel Research, Vol. 3, Issue 2, 2019

Geleneksel Bir Ürün Olarak Kastamonu Pastırması

Nuray TÜRKER, B. Meltem TÜRKMEN, Esra CAYMAZ

nedeniyle pastırma üreticilerinin sayvanları genellikle bu bölgede bulunmaktadır. Kuruyan etler, ilk asılmasından sonra ağırlıklarının \% 50`sini kaybeder.

Pastırma, pastırma yazı denilen ekim-kasım aylarında kurutulur. Pastırmanın nemli bir ortamda kurutulmaması gerekir. Sayvanlara asılan et hava şartlarına bağlı olarak 1-1,5 ay kurutulur. Kuruyan etlerin çemenlenecek bölümleri çemenlenir. Çemenin kalınlığı bir bıçak sırtı kadar yani yaklaşık 3-5 mm'dir. Kastamonulular az yağlı pastırmayı tercih ederler. Ancak çemensiz pastırmada etin yağlı kısımları kullanılır. Çemensiz pastırma yapımında etin yağlı olan kaburga kısmı kullanılır. Çemensiz pastırmadan genellikle pastırmalı pide yapılmaktadır.

Kastamonu'da Eylül ayında başlayan pastırma üretimi Mart ayına kadar devam etmektedir. Yaz aylarında hava koşulları uygun olmadığı için pastırma üretimi yapılmaz.

Pastırma yapımında kullanılan çemen; çemen unu, Taşköprü sarımsağı ve çeşitli baharatlardan hazırlanır. Baharat olarak kırmızıbiber (tatlı, acı), kimyon, tuz, v.b. kullanılır."

Kastamonu ilinin tescilli coğrafi ürünleri arasında bulunan Taşköprü sarımsağı çemene ayrı bir lezzet katmaktadir.

Kastamonu pastırmasının özelliklerinden biri de pastırmanın pastırmacı tarafından kütük veya mermer üzerinde keskin bir bıçakla kâğıt gibi ince şekilde doğranmasıdır. Fabrikasyon veya makine kesimi makbul sayılmaz (Kastamonu Valiliği, 2009). Pastırmanın doğrandığı kütük kavak gibi yumuşak bir ağaçtan yapılır.

Kastamonu pastırması 3 kategoride hazırlanır. Bunlar (Kastamonu Valiliği, 2009);

Yağsız Pastırmalar: Kuşgömü, bohça (eğrice) kenar, but dilmesi, şeker-pare, bacak.

Orta Yağlı Pastırmalar: Sırt, omuz, kürek, mehle.

Çok Yağlı Pastırmalar: Döş.

\section{Kastamonu'da Üretilen Pastırma Miktarı, Maliyet ve Pastırma Satışları}

Yapılan görüşmelerden elde edilen bilgiler Kastamonu'da yılda ortalama 200 ton pastırma üretildiğini göstermektedir. $\mathrm{Bu}$ oran Türkiye'deki y1llık pastırma üretiminin \%10'una karşılık gelmektedir. Kastamonu'da pastırmanın kilosu 110 TL'den satılmaktadır (2018 yılı rakamları). Dolayısı ile pastırmanın şehir ekonomisine katkısı yıllık 22 milyon TL civarındadır.

K2: “...Y1lda 50 ton civarında pastırma üretmekteyiz. .....Pastırma üretiminde $\% 60$ fire verilir. Bir pastırmanın maliyetinde $\% 15$ işçilik bulunmaktadır. Bir kilo pastırma ortalama $\% 20$ kar bırakmaktadır. .....Elde edilen gelir etin kalitesine göre değişmektedir.

..Ürettiğimiz pastırmanın \% 70'i şehir dişına gönderilmektedir. Kastamonu'ya ziyaret için gelenler giderken yanlarında pastırma götürmektedir. S1k sık hediyelik olarak kargo ile il dışına da göndermekteyiz. İstanbul'da Günaydın'a, Doğuş Holding'e pastırma satıyoruz. Pahalı olduğu için yaygın olarak restoranlara satamıyoruz. Ancak kaliteli restoranlar ürünlerimizi satın alabiliyor"

K3: “...Talebe göre yılda 5-6 tona yakın pastırma üretmekteyiz. Ancak firesi yüksek. Astığımız et $\% 50$ fire vermektedir. .....1 kilo pastırmanın 80 liraya yakın maliyeti var. ....Daha çok kargo ile il dışına göndermekteyiz. Pastırmanın \%70'i şehir dışına gönderilir. \%30'u bölgede tüketilir." 


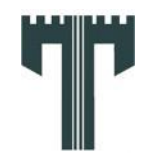

Gastroia: Journal of Gastronomy and Travel Research, Vol. 3, Issue 2, 2019

Geleneksel Bir Ürün Olarak Kastamonu Pastırması

Nuray TÜRKER, B. Meltem TÜRKMEN, Esra CAYMAZ

K4: “...Y1lda ortalama 25-50 ton arasında pastırma üretiyoruz. Bu rakam y1llara ve talebe göre değişiklik gösteriyor. Yıllar geçtikçe üretim arttı. ....\%50 fire veriyor. 10 kilo et tuzlanıp yıkandıktan sonra 7 kiloya düşer ve askıya alınıp en son pastırma halini alana kadar yaklaş1k \%50 fire verir. Pastırmanın kilo maliyeti yaklaşık 90 TL'dir.

....Ürünlerimizin \%60-70’i il dışına kargo ile gönderilmektedir. Kastamonu'daki diğer işletmeler de göz önünde bulundurulduğunda Kastamonu'da yaklaşık olarak yılda 200 ton pastırma üretildiği söylenebilir."

\section{Kayseri Pastırması ile Kastamonu Pastırması Arasındaki Farklar}

Pastırma üretimi alanında Kayseri en popüler il olmasına karşın Kastamonu pastırması lezzet bakımından daha üstün kabul edilmektedir. Kayseri pastırması endüstriyel olarak, Kastamonu pastırması ise halen küçük atölyelerde el emeği ile üretilmekte ve geleneksel üretim tekniği kullanılmaktadır.

K3: “...Fabrikasyon bir ürün olan Kayseri pastırması içerisinde koruyucu maddeler ve katkı maddeleri bulunmaktadır. Oysaki Kastamonu pastırması tamamen doğaldır ve içerisine hiçbir katkı maddesi konulmamaktadır."

K4: “...Raf ömrünün uzun olması için Kayserililer koruyucu maddeler ve katkı maddeleri kullanmaktadırlar. Kurutma işlemi fabrikalarda makinelerle yapılmaktadır. Hâlbuki biz pastırmayı tamamen doğal şartlarda kurutarak, içerisine koruyucu ve katkı maddesi koymadan üretmekteyiz. Keza Kayseri pastırması makinelerle doğranmaktadır. Kastamonu pastırması ise sizin de gördüğünüz gibi el ile doğranır. İçerisinde tutucu madde bulunmadığı için çemen doğranan pastırmalarda kalıp halinde bulunmaz."

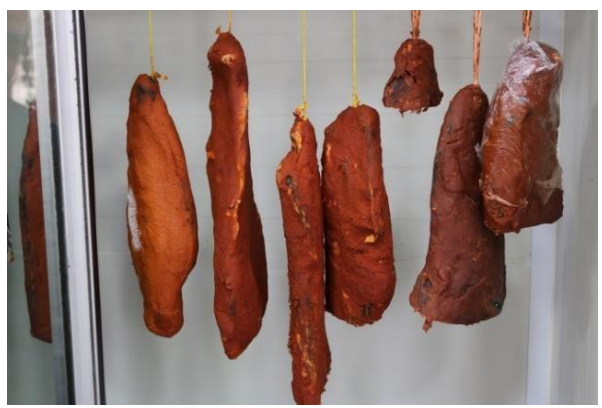

Resim 1. Çemenli Pastırma

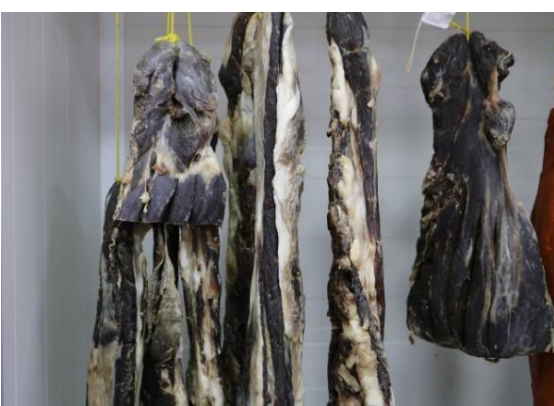

Resim 2. Çemensiz Pastırma

Tablo 2: Kastamonu Pastırması ile Kayseri Pastırması Arasındaki Farklar

\begin{tabular}{|l|l|}
\hline Kastamonu Pastırması & Kayseri Pastırması \\
\hline Geleneksel yöntemlerle üretilir. & Endüstriyel üretim söz konusudur. \\
\hline Geleneksel kurutma yöntemleri kullanılır. & Pastırmalar kurutma odalarında kurutulur. \\
\hline $\begin{array}{l}\text { Dışına sürülen çemen katkı maddesi } \\
\text { kullanılmadan hazırlanır ve pastırma kesilirken } \\
\text { çemen dağıılır. }\end{array}$ & $\begin{array}{l}\text { Dışına sürülen çemenin içerisine kimyasal } \\
\text { maddeler konarak saklama süresi uzatılır, } \\
\text { kesilirken çemenli kısım dağılmaz. }\end{array}$ \\
\hline $\begin{array}{l}\text { Geleneksel kesim yöntemi olan keskin bir bıçak } \\
\text { kullanılarak elle kesilir. }\end{array}$ & Makine ve satır kullanılarak kesilir. \\
\hline Çok ince kesilir. & Kastamonu pastırmasına göre daha kalın kesilir. \\
\hline Yalnızca Kastamonu'da üretilir ve satılır. & $\begin{array}{l}\text { Endüstriyel bir ürün olduğu için yaygın dağıtım } \\
\text { yapılır. }\end{array}$ \\
\hline
\end{tabular}




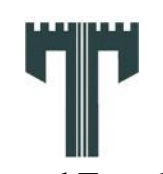

Gastroia: Journal of Gastronomy and Travel Research, Vol. 3, Issue 2, 2019

Geleneksel Bir Ürün Olarak Kastamonu Pastırması

Nuray TÜRKER, B. Meltem TÜRKMEN, Esra CAYMAZ

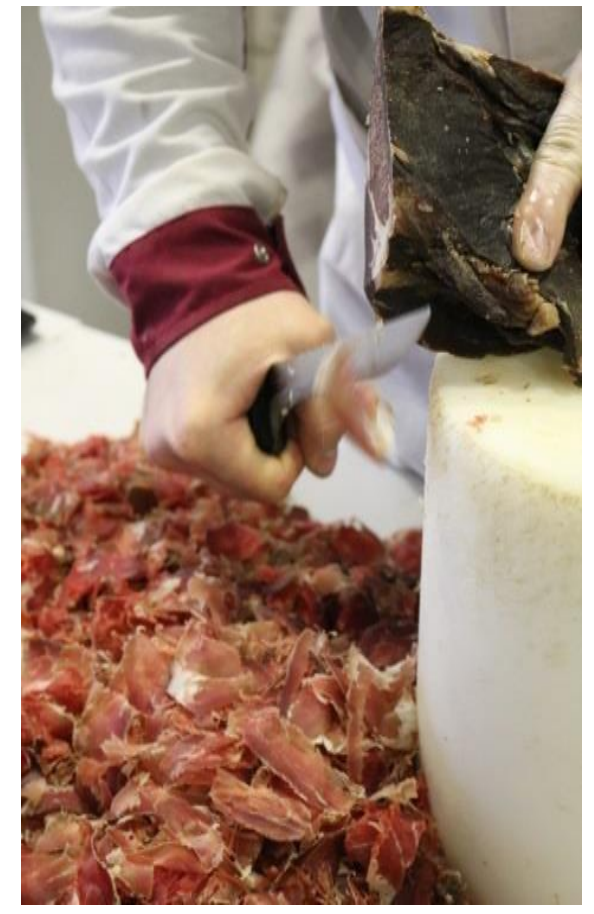

Resim 3. Bıçak ile Kesilen Kastamonu Pastırması

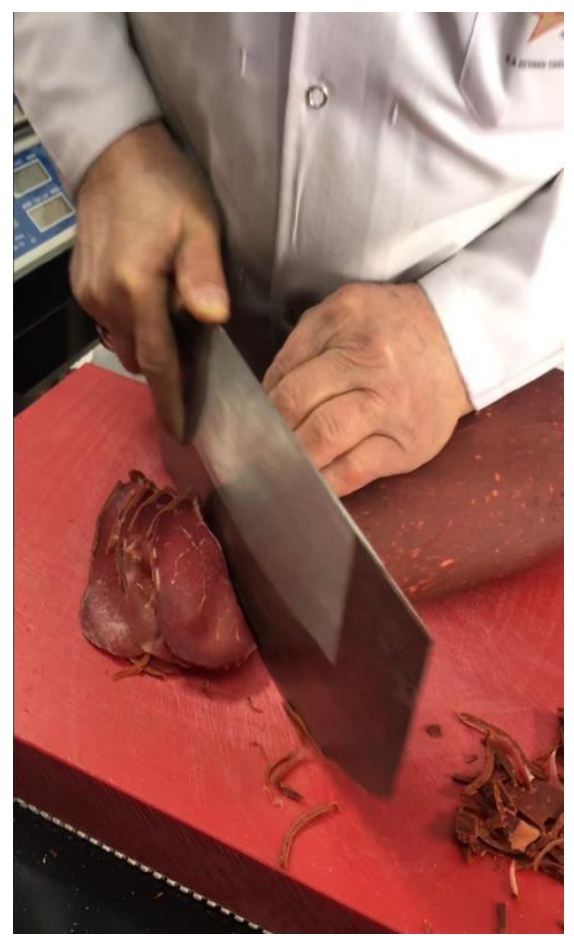

Resim 4. Satır ile Kesilen Kayseri Pastırması

\section{Kastamonu'da Pastırma ile Yapılan Yemekler}

Kastamonu'da pastırma ağırlıklı olarak kahvaltıda tüketilmektedir. Pastırma çok çeşitli yemeklerin yapımında kullanılmamaktadır. Pastırma ile yapılan yiyeceklerin başında çemensiz pastırmadan hazırlanan pastırmalı ekmek gelmektedir.

K2: “...En çok pastırmalı ekmek tercih edilir. Pastırmalı ekmek için iç malzemesini biz hazırlarız, fırına götürür pişirirler. Özellikle Cumartesi-Pazar günleri soğanları doğrayıp hazır bekletiriz. Müşteri istediğinde çemensiz pastırmayı doğrayıp soğan, kırmızıbiber, karabiber ve kimyon ile harmanlıyoruz. Bu harçta pastırma miktarı kadar soğan bulunur. Fırınlar simitlik hamurdan hazırlıyorlar bu ekmekleri. ........Pastırmalı ekmek içi evlerde de hazirlaniyor." 


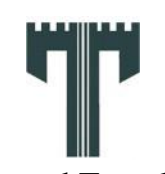

Gastroia: Journal of Gastronomy and Travel Research, Vol. 3, Issue 2, 2019

\section{Geleneksel Bir Ürün Olarak Kastamonu Pastırması}

Nuray TÜRKER, B. Meltem TÜRKMEN, Esra CAYMAZ

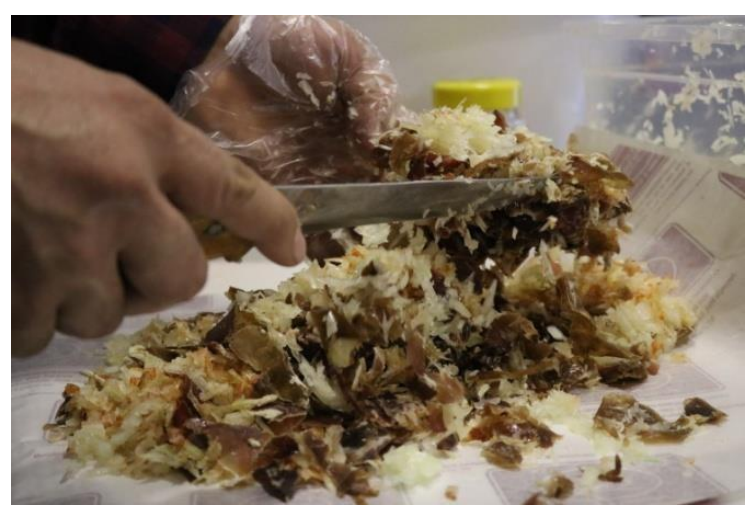

Resim 5. Pastırmalı ekmek için iç harcı

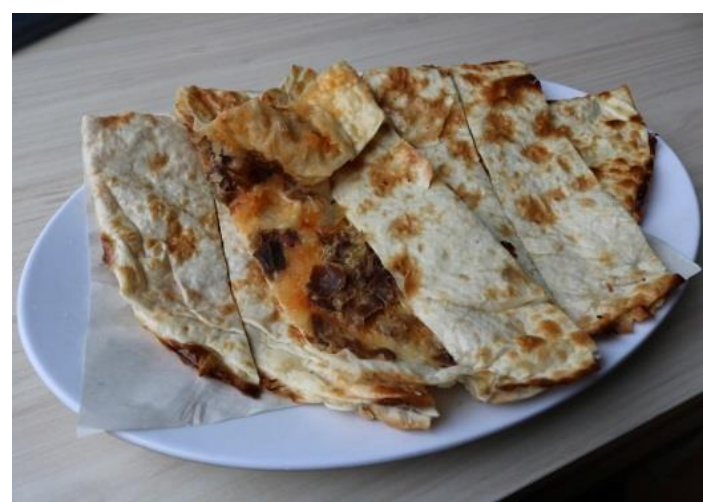

Resim 6. Pastırmalı Ekmek

\begin{tabular}{|c|}
\hline $\begin{array}{c}\text { Pastırmalı Ekmek } \\
\text { (1 Ekmek için) }\end{array}$ \\
\hline Malzemeler \\
\hline $\begin{array}{l}\text { - 200-250 gr. simit hamuru } \\
\text { - } 300 \text { gr çemensiz pastırma } \\
\text { - } 3 \text { büyük baş beyaz soğan } \\
\text { - Bir tutam karabiber } \\
\text { - Bir tutam kimyon } \\
\text { - Bir tutam kırmızı biber } \\
\text { - Tereyağı (üzerini yağlamak için) }\end{array}$ \\
\hline Yapılıșı \\
\hline $\begin{array}{l}\text { Kastamonu'da pastırmalı ekmek firınlarda pişirilir. Pastırmalı iç } \\
\text { pastırmacılarda satılır. Ekmeğin içine konacak çemensiz pastırma bıçakla ince } \\
\text { ince doğranır. Beyaz soğanlar da aynı şekilde doğranır. Müşteri, geldiği } \\
\text { zaman istediği miktara göre çemensiz pastırma, doğranmış soğan, kırmızı } \\
\text { biber, karabiber ve kimyonu iyice karıştırılarak müşteriye verilir. Bu } \\
\text { karışımda pastırma kadar soğan bulunur. Satın alınan pastırmalı ekmek içi } \\
\text { fırına götürülür. } 200 \text { - } 250 \text { gramlık simitlik hamur pazısı tezgâhın üzerinde } \\
\text { merdane ile açılır. Açılan bu yufkanın yarısına } 300 \text { gr. pastırmalı ekmek içi } \\
\text { konulup yayılır. Diğer yarısı üzerine kapatılır, uçları parmakla bastırılır. Orta } \\
\text { sıcaklıktaki firında pişirilir. } \\
\text { Pişirilen ekmeklerin tercihe göre üstü tereyağı ile yağlanır. Tercihe göre } \\
\text { kesilerek ya da elle bölüp yenir. Esas usul elle bölünerek yenmesidir. } \\
\text { Kastamonu'da pastırmalı ekmek her mevsim yapıllmaz. Özellikle kış } \\
\text { aylarında daha çok yapılır. }\end{array}$ \\
\hline
\end{tabular}

Kaynak: Kastamonu Valiliği Ağız Tadıyla Kastamonu Mutfağı, 2009 


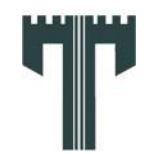

Gastroia: Journal of Gastronomy and Travel Research, Vol. 3, Issue 2, 2019

Geleneksel Bir Ürün Olarak Kastamonu Pastırması

Nuray TÜRKER, B. Meltem TÜRKMEN, Esra CAYMAZ

\begin{tabular}{|c|}
\hline Ispanaklı Mıhlama (6 kişilik) \\
\hline Malzemeler \\
\hline $\begin{array}{l}\text { - } 1 \text { kg. 1spanak } \\
\text { - } 2 \text { büyük boy soğan } \\
\text { - } 200 \text { gr. pastırma } \\
\text { - } 2 \text { kaşı tereyağı } \\
\text { - } 6 \text { yumurta } \\
\text { - } 1 \text { yemek kaşığı domates salçası } \\
\text { - Tuz } \\
\text { - Karabiber }\end{array}$ \\
\hline Yapılışı \\
\hline $\begin{array}{l}\text { Ispanaklar ayıklanıp yıkanır. Suyu sarktıktan sonra ince ince doğranır. Bir } \\
\text { büyük tencerede (tava biçimli pilav tenceresi daha iyi olur) doğranmış soğan } \\
\text { kavrulur, üzerine doğranmış pastırma ilave edilerek birkaç dakika çevrilir. } \\
\text { Üzerine doğranmış ıspanak ilave edilerek kavrulur. Kavurma işlemi bitince } \\
\text { biraz su, salça, karabiber ve tuz (salça tuzlu olabileceği için dökülen tuz } \\
\text { miktarına dikkat edilmelidir) ilave edilerek pişirilir. Bu noktada ıspanaklar } \\
\text { yumurta eklendiğinde bir süre daha pişeceği için tam olarak pişirilmemelidir. } \\
\text { Pişen ıspanaklar tencereye yayılarak üzerine kişi sayısına göre yumurta kırılır. } \\
\text { Yumurtaların üzerine tuz dökülür. Yumurtalar pişince servis edilir. }\end{array}$ \\
\hline
\end{tabular}

Kaynak: Müyesser Türker, 2019.

K1: “...Kastamonu pastırması ile pastırmalı pide, mihlama (pastırma ve soğan konan bir yemek), pastırmalı kuru fasulye, pastırmalı pilav (çemensiz pastırma ile yapılır) yaparız. Çiğ olarak da genellikle kel simit (susamsız simit) ile yenir. Bir porsiyon pastırmalı ekmek için; 100 gr çemensiz pastırma, 150 gr soğan ve baharat kullanılır."

\section{SONUÇ, DEĞERLENDİRME VE ÖNERİLER}

Çalışmanın temel amacı, Kastamonu pastırmasının üretim sürecinin, Kastamonu'da pastırmacılığının tarihinin ve pastırmadan yapılan yemeklerin ortaya konulmasıdır. $\mathrm{Bu}$ bağlamda ilgili literatür taranmış ve Kastamonu'da pastırmacılık yapan dört işletme ile görüşülerek bilgi toplanmıştır.

Kastamonu'da pastırmacılığın bilinen tarihi 19. yüzyılın sonlarına kadar uzanmaktadır. Kastamonu'nun yöresel ürünlerinden biri olan pastırmanın üretimi halen devam etmekte olup bu üretim geleneksel yöntemlerle yapılmaktadır. Bu da Kastamonu pastırmasının önemini arttırmaktadır. Pastırmada kullanılan etin Kastamonu yöresinde yetișen sığırlardan elde edilmesi, koruyucu madde kullanılmaması, çemeninde kullanılan aromatik Kastamonu Taşköprü sarımsağı, pastırmanın el ile kesilmesi pastırmanın lezzetini arttırmaktadır. Bununla birlikte, bölgede hayvancılığın azalmasına bağlı olarak siyah sığır ırkının ve pastırma üretiminde önemli bir yere sahip olan Taşköprü sarımsağının azalması pastırmanın sürdürülebilirliğini tehdit etmektedir.

Kastamonu'da pastırmacılık yapan işletmeler genellikle aile işletmesidir. Yeni kuşaklar aile işini devam ettirme niyetindedirler. Üretimde kullandıkları reçeteler yüzyılların bilgi birikimine ve tecrübesine dayanmaktadır. 


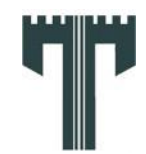

Gastroia: Journal of Gastronomy and Travel Research, Vol. 3, Issue 2, 2019

\section{Geleneksel Bir Ürün Olarak Kastamonu Pastırması}

Nuray TÜRKER, B. Meltem TÜRKMEN, Esra CAYMAZ

Kastamonu pastırmasının \% 70'i Kastamonu dışında tüketilmektedir. Bu tüketimin önemli bir kısmını Kastamonu'yu ziyaret eden kişilerin hediyelik olarak pastırma satın almaları oluşturmaktadır. Ayrıca başka şehirlerde oturan Kastamonu pastırmasının lezzetini bilen kişiler üretici işletmelerden pastırma talep etmekte ve kargo ile ürün gönderilmektedir.

Kastamonu'da pastırmanın yemek yapımında kullanılması oldukça sınırlıdır. Pastırma ile yapılan yiyeceklerin en önemlisi pastırmalı pidedir. Ayrıca içine pastırma konarak mıhlama, kuru fasulye, pastırmalı pilav (çemensiz pastırma ile yapılır) gibi yemekler de hazırlanmaktadır. Pastırma çĭg olarak ise genellikle kel simit (susamsız simit) ile tüketilmektedir.

Kastamonu'yu yılda ortalama 800 bin kişi ziyaret etmektedir (Kastamonu İl Kültür ve Turizm Müdürlüğü, 2018). Kültür turizmi destinasyonu olarak son yıllarda dikkate değer bir gelişme gösteren Kastamonu sahip olduğu yöresel lezzetleri ile de önemli bir gastronomi turizmi potansiyeline sahiptir. $\mathrm{Bu}$ potansiyelin yerel yönetimlerce ve ilgili paydaşlarca (turizm işletmeleri, sivil toplum kuruluşları, yerel halk v.b.) iyi değerlendirilmesi halinde Kastamonu turizminin gelişmesi, rekabet edebilmesi ve bölgede öne çıkan bir turizm destinasyonu olması sağlanabilir.

Kastamonu pastırmasının sürdürülebilirliğini sağlamak için geliştirilen öneriler aşağıda verilmektedir:

- Gelenekselliğinin korunması ve üretiminin devam etmesi için çırak yetiştirmeye önem verilmelidir.

- Coğrafi işaret alınarak Kastamonu pastırması tescil edilmelidir.

- Kastamonu pastırmasının somut olmayan kültürel miras listesine alınması için çalışmalar yürütülmelidir.

- Pastırmaya dayalı yeni yiyecekler üretilebilir.

- Pastırma, Kastamonu'ya gelen kültür turlarının tur programlarına dahil edilmelidir. Böylece kültür turları başka turizm ürünleri ile bütünleștirilerek zenginleștirilebilir.

- Kastamonu'da gastronomi turizminin gelişmesi için yerel yönetimlerce gerekli çalışmalar yapılmalıdır. Kastamonu sadece pastırması ile değil diğer yöresel ürünleri (Kastamonu sucuğu, etli ekmek, banduma, Ecevit çorbası, Simit tiridi, Biran / Kuyu kebabı, Köle hamuru, Cırık tatlısı, Üryani eriği hoşafı, çekme helva, Cide helvası / Cidella, Hüryemez elması, Kastamonu Eğşisi, Siyez bulguru ve unu, Üryani eriği, Tosya pirinci, çeşitli mantarlar v.b.) ile de önemli bir gastronomi şehridir. Yapılan araştırmalar (Avcı ve Şahin, 2014) Kastamonu'da 812 adet yemek türü olduğunu ve bunlardan 500 tanesinin diğer yöreler tarafindan bilinmediğini ortaya çıkarmıştır.

- Turizm fuarlarında pastırma tadımı yapılarak Kastamonu pastırmasının tanıtımı yapılmalidir.

- Pastırma, kitle iletişim araçları, tanıtım filmleri (reklam vd.), sosyal medya, kitap ve broşürler, internet v.b. kullanılarak tanıtılmalı ve farkındalık yaratılmalıdır. 


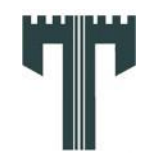

Gastroia: Journal of Gastronomy and Travel Research, Vol. 3, Issue 2, 2019

Geleneksel Bir Ürün Olarak Kastamonu Pastırması

Nuray TÜRKER, B. Meltem TÜRKMEN, Esra CAYMAZ

\section{KAYNAKÇA}

Aksu, M. İ. ve Kaya, M. (1999). Erzurum Piyasasında Tüketime Sunulan Pastırmaların Bazı Fiziksel, Kimyasal ve Mikrobiyolojik Özellikleri. Journal of Veterinary and Animal Sciences, 25 (3), 319-326.

Anadolu Lezzet Envanteri (2016). http://www.mutfakdostlari.org.tr/wpcontent/uploads/2016/12/ESSEDRA-brosur-2016-SON.pdf.

And, M. (2011). 16. Yüzyılda İstanbul Kent - Saray - Günlük Yaşam. İstanbul: YK Yay.

Aslan, Z., Güneren, E. ve Çoban, G. (2014). Destinasyon Markalaşma Sürecinde Yöresel Mutfağın Rolü: Nevşehir Örneği. Journal of Tourism and Gastronomy Studies, 2 (4), 3-13. Avc1, M. ve Şahin, İ. (2014) Geleneksel Kastamonu Mutfağı ve Yemek Kültürü, Giresun Üniversitesi Karadeniz Sosyal Bilimler Dergisi, 6, Karadeniz Özel Sayıs1: 31-56.

Devlet İstatistik Enstitüsü Başkanlığı (2012). Turizm Geliri ve Diğer Harcamalar. 20112012 III. Dönem (Temmuz - Eylül) anketi. www.die.gov.tr

Gök:A., Ceyhun Sezgin, A. ve Yıldırım, F. (2017). Gastronomi Alanında Maraş Tarhanasının Değerlendirilmesi. Aydın Gastronomy, 1 (1), 61-70.

Gülensoy, T. (2011). Türkiye Türkçesindeki Türkçe Sözcüklerin Köken Bilgisi Sözlüğü I-II. Ankara: TDK Yay.

Gürbüz, Ü. (2004). Pastırma Üretiminde Değişik Tuzlama Tekniklerinin Uygulanması ve Kaliteye Etkileri. Veteriner Bilimleri Dergisi, 20 (2), 5-20.

Kastamonu İl Kültür ve Turizm Müdürlügü (2018). Turizm İstatistikleri.

Kastamonu Valiliği (2009). Ağız Tadıyla Kastamonu Mutfağı, Kastamonu Valiliği Yayınları.

Kıliç, B. (2009). Current trends in traditional turkish meat product and cuise. Food Science and Tecnology, 42, 1581-1589.

Kılıç: ve Albayrak, A. (2012). İslamiyetten Önce Türklerde Yiyecek ve İçecekler. Journal of Turkish Studies, 7 (2), 707-716.

Kızıldemir, Ö., Öztürk, E. ve Sarışı, M. (2014). Türk Mutfak Kültürünün Tarihsel Gelişiminde Yaşanan Değişimler. AÏBÜ Sosyal Bilimler Enstitüsü Dergisi, 14 (3), 191 210.

Kızıldemir, Ö., Öztürk, E. ve Sarışı,, M. (2017). Cumhuriyet Dönemi Türk Mutfak Kültürünün Özellikleri ve Yaşanan Değişimler. VI. Ulusal II. Uluslararası Doğu Akdeniz Turizm Sempozyumu.

Kivela, J., Crotts, J. C. (2005) Gastronomy Tourism, Journal of Culinary Science \& Tourism, 4 (2-3): 39-55.

Kök, F. (2003). Pastırma Üretim Teknolojisini Geliştirme Çabaları. Uludă̆ Üniversitesi Veteriner Fakültesi Dergisi, 22 (1-2-3), 109-114.

Kut, T. (1985). Açıklamalı Yemek Kitapları Bibliyografyası (Eski Harfli Yazma ve Basma Eserler). Ankara: KTB Yay. 


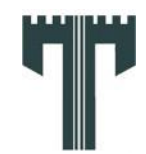

Gastroia: Journal of Gastronomy and Travel Research, Vol. 3, Issue 2, 2019

Geleneksel Bir Ürün Olarak Kastamonu Pastırmast

Nuray TÜRKER, B. Meltem TÜRKMEN, Esra CAYMAZ

Memiş, E. ve Ersoy, Y. (2007). Geleneksel Gıda Muhafaza Yöntemleri. 38. ICANAS Uluslararası Asya ve Kuzey Afrika Çalışmaları Kongresi, 10-15 Eylül, Ankara.

Milli Eğitim Bakanlığı (2016). Gıda Teknolojisi Et ve Et Ürünleri Teknolojisi, http://megep.meb.gov.tr/mte_program_modul/moduller/Et\%20ve\%20Et\%20\%C3\%9Cr\%C 3\%BCnleri\%20Teknolojisi.pdf Erişim: Ocak 2018

Nizamlığlu, M., Doğruer, Y., Gürbüz, Ü. Ve Kayaardı: (1998). Çeşitli Çemen Karışımlarının Pastırma Kalitesine Etkisi I: Kimyasal ve Duyusal Nitelikler. Tr. J. of Veterinary and Animal Sicences, 22, 299-308.

Özkan, N. (2013). Pastırma Sözü Üzerine. Dil Araştırmaları, 13, 45-55.

Öztürk, İ. (2015). Presence, changes and technological properties of yeast species during processing of pastirma, a Turkish dry-cured meat product. Food Control, 50, 76-84.

Rızaoğlu, B., Ayazlar, R.A. ve Gençer, K. (2013).” Yiyecek Deneyimiyle İlgili Bireysel Eğilimlerin Sosyo-Demografik Özellikler Açısından Değerlendirilmesi: Kuşadası'na Gelen Yabanc1 turistler Örneği”. 14. Ulusal Turizm Kongresi Bildiriler Kitabl, 05-08 Aralık. Kayseri: Erciyes Üniversitesi Turizm Fakültesi: 669- 687.

Sarı, N. (1982). "Osmanlı Sarayında Yemeklerin Mevsimlere Göre Düzenlenmesi ve Devrin Tababetiyle İlişkisi”. Türk Mutfă̆ı Sempozyumu Bildirileri 31 Ekim - 1 Kasım 1981. Ankara: KTB Yay.: 245-255.

Sirşe J. (2014) "Gastronomic Cities: City Strategy on Gastronomy as a Tool for Tourism and Employment Development," Baseline Study.

Telfer, D. J. and Hashimoto, A. (2013) Wine and culinary tourism in Niagara. In M. Ripmeester, P. Mackintosh and C. Fullerton (eds) The World of Niagara Wine. Waterloo (pp.281-299). Wilfrid Laurier University Press.

Telfer, D.J.ve Wall, G. (2000). "Strengthening backward economic linkages: Local food purchasing by three Indonesian hotels". Tourism Geographies, Volume: 2, Number:4, 421-447.

Tosun, D. ve Demirbaş, N. (2012). Türkiye'de Kırmızı Et ve Et Ürünleri Sanayiinde Gıda Güvenliği Sorunları ve Öneriler, U. Ü. Ziraat Fakültesi Dergisi, 26 (1): 93-101.

World Tourism Organization (2012) Global Report on Food Tourism: Madrid.

Türker, Müyesser (2019). Yemek tarifi ile ilgili görüşme.

Yaşin, M. (2016). http://www.hurriyet.com.tr/turkiyenin-gastronomi-baskenti-neresi40063697. Erişim Tarihi (12 Eylül 2016).

Yıldırım, Y., Onmaz, N. E., Gönülalan, Z., Al:, Yıldırım, A., Karadal, F. ve Pamuk, Ş. (2017). Microbiological quality of pastrami and associated surfaces at the point of sale in Kayseri, Turkey. Public Health, 146, 152-158.

\section{Görüșme Yapılan Kișiler:}

Hasan Ayanoğlu, Gurme Pastırma ve Sucukları.

Sedat Tabakoğlu, Tabakoğlu Pastırma ve Sucuk.

Emine Yüceilyas, Ellezler Pastırma.

Tolgahan Karaosmanoğlu, Canlılar Pastırma ve Sucuk. 